\title{
Grid Investment and Support Schemes for Renewable Electricity Generation
}

\author{
Johannes Wagner*
}

\begin{abstract}
The unbundling of formerly vertically integrated utilities in liberalized electricity markets led to a coordination problem between investments in the regulated electricity grid and investments into new power generation. At the same time investments into new generation capacities based on weather dependent renewable energy sources such as wind and solar energy are increasingly subsidized with different support schemes. Against this backdrop this article analyzes the locational choice of private wind power investors under different support schemes and the implications on grid investments. I find that investors do not choose system optimal locations in feed-in tariff schemes, feed-in premium schemes and subsidy systems with direct capacity payments. Consequently, inefficiencies arise if transmission investment follows wind power investment. A benevolent transmission operator can implement the first-best solution by anticipatory investment behavior, which is however only applicable under perfect regulation. Alternatively a location dependent network charge for wind power producers can directly influence investment decisions and internalize the grid integration costs of wind power generation.
\end{abstract}

Keywords: Renewable energy investment, Transmission investment, Coordination problem, External effects

https://doi.org/10.5547/01956574.40.2.jwag

\section{INTRODUCTION}

A large number of electricity systems, for example in the United States or Europe, have been liberalized and restructured over the last decades. A central part of these restructuring efforts is unbundling, which describes the vertical separation of the monopolistic network from the potentially competitive parts of the system, namely generation, wholesale and retail. In unbundled electricity systems, separate entities such as private generation investors and regulated transmission operators make investment decisions based on their individual agenda. Nevertheless, there exist strong interactions between these decisions because of the physical properties of the electricity system, which leads to a coordination problem between generation investment and grid investment. New power plants can for example increase network congestion and therefore force extensions which could be avoided by choosing a different location for the investment. ${ }^{1}$

1. Kunz (2013) finds that investment into coal fired power generation in northern Germany significantly increases congestion costs. Due to lower inland transportation costs for coal, locations at the North Sea coast in northern Germany are

* Department of Economics and Institute of Energy Economics, University of Cologne. Vogelsangerstraße 321a, 50827 Köln, Germany. E-mail: johannes.wagner@ewi.uni-koeln.de. 
To address the outlined coordination problem, a proactive approach to transmission planning is increasingly proposed, in which the transmission operator attempts to optimize the aggregated electricity system by taking into account consumer welfare, generation costs and transmission costs. Consequently, the transmission planner explicitly considers the effect of grid extensions on the decision problem of generation investors in order to implement an overall welfare optimal system configuration. Anticipatory planning processes therefore extend the traditional approaches to transmission investment, which focus primarily on reliability issues and technical feasibility instead of an economically optimal total system configuration.

The need for cost effective transmission planning is intensified by the increasing importance of electricity generation from intermittent renewable energy sources such as wind and solar. Because of the weather dependency of these energy sources, the best locations for wind and solar power plants are typically distributed and located away from load centers. As a result, the integration of large amounts of generation capacity based on wind and solar energy into the electricity system requires substantial investments into the electricity grid. ${ }^{2}$ Despite these integration challenges, renewable energy investors face favorable regulations regarding grid connection in many countries, which often oblige the grid operator to connect new generation capacities based on renewable energy sources. ${ }^{3}$ Consequently, the regulatory framework frequently promotes reactive approaches to transmission planning.

Investment into electricity generation from renewable energy sources is largely driven by support mechanisms such as feed-in tariff systems, feed-in premium systems or capacity subsidies. ${ }^{4}$ A crucial difference between these subsidy systems is how producers of renewable electricity are exposed to market signals. Under feed-in tariffs renewable generators receive a fixed payment for every produced kilowatt hour of electrical energy. Consequently, generators are entirely isolated from market signals. With capacity subsidies on the other hand, producers of renewable energy are fully exposed to market signals because they generate revenue only due to electricity sales in the wholesale market. Feed-in premiums combine the described approaches by paying a fixed premium on top of the wholesale electricity price to renewable energy producers.

Against the described backdrop, this paper analyzes the influence of the subsidy scheme for renewable electricity generation on the locational choice of renewable energy investors and the subsequent implications for grid investments. Of particular interest are inefficiencies which arise due to deviations from the socially optimal allocation of renewable generation capacities when transmission investment follows renewable energy investment. Building on that, anticipatory behavior of the transmission operator is assessed as a potential remedy to avoid inefficient system configurations. To analyze these issues a highly stylized model with one demand node, two possible

more attractive for private generation investors compared to locations in southern Germany if congestion costs are not internalized.

2. The required grid investments in the European electricity system to reach the European $\mathrm{CO}_{2}$ reduction and renewable energy targets are analyzed in Fürsch et al. (2013). The results indicate that optimal network extension requires transmission investments of more than 200 billion EUR until 2050. A similar analysis for the United States can be found in National Renewable Energy Laboratory (2012). The required average yearly transmission investment to reach a share of renewable electricity generation of $80 \%$ by 2050 is estimated in a range between 6.4 and 8.4 billion USD.

3. See Swider et al. (2008) for a discussion of the conditions for grid connection of renewable electricity generation in Europe.

4. An overview of support policies for renewable electricity generation in OECD and non-OECD countries is provided in International Energy Agency (2015). The general question of the economic justification of renewable energy support instead of direct $\mathrm{CO}_{2}$ pricing is not part this paper. The most common argument for renewable energy support policies are market failures due to learning spillovers. See for example Fischer and Newell (2008) or Gerlagh et al. (2009) for an analysis. An extensive review of literature on the rationale of support policies for renewable energies can be found in Fischer (2010).

All rights reserved. Copyright (C) 2019 by the IAEE. 
locations for renewable generation investment and lumpy transmission investment is developed. Electricity generation at the two locations is stochastic with different total expected generation and imperfectly correlated generation patterns. Renewable energy investments are subsidized by a feed-in tariff scheme, a feed-in premium system or direct capacity payments in order to reach an exogenous renewable target. ${ }^{5}$ The analysis is conducted for wind power, however the results apply for all intermittent and location dependent renewable energy sources such as solar or marine energy.

The analysis shows, that none of the assessed support mechanisms guarantees an efficient allocation of generation capacities. In a feed-in tariff system, investors develop only the wind location with the highest expected generation because they are isolated from market signals. Consequently, social benefits from developing both locations, which arise because of the imperfect correlation between wind generation at both sites, are not realized. With capacity payments on the other hand, investors do receive market signals but grid investment costs are external. As a result, investors diversify locations even if the social benefit does not justify the additional grid investment costs, which are necessary to integrate the second wind location into the system. In a feed-in premium system, investors generate revenue from fixed premium payments and from market participation. Hence, investors act either as in a feed-in tariff system or as in a system with capacity payments, depending on which of the two revenue streams dominates. Building on these results I find, that the efficient system configuration can be implemented by anticipatory transmission investment. The results imply, that the locational choice of investors depends on the choice of the subsidy mechanism and that a more active role of the grid operator can help to efficiently integrate renewable energy sources into electricity systems.

The described results are derived in a stylized model framework. Nevertheless, the implications are of high policy relevance. The coordination between investment into generation capacities based on renewable energy sources and investment into transmission lines is a practical issue in a large variety of countries which plan to increase the share of renewable energy in electricity generation. Practical examples for the United States, the European Union, Mexico, Panama, Egypt, Brazil and the Philippines are provided in Madrigal and Stoft (2012). Additionally, numerical studies show that the analyzed inefficiencies are already of relevance in practice. Obermüller (2017) shows that the current regulatory framework in Germany overincentivizes investment in Northern Germany because transmission bottlenecks are not accounted for. Similarly, Bjørnebye et al. (2018) show for Norway that wind power investment at inefficient locations, which is encouraged by the current regulation, could increase the required grid expansion by $55 \%$. Building on these practical examples, the present paper derives some general conclusions and intends to derive practical implications for policy makers based on theoretical economics.

The paper is mainly related to two literature streams. The first relevant literature stream examines the efficiency of different subsidy schemes for electricity generation from renewable energy sources. Hiroux and Saguan (2010) give an overview of the advantages and disadvantages of different support schemes with respect to the integration of large amounts of wind power into the European electricity system. They argue that support schemes should expose wind power producers to market signals in order to incentivize system optimal choices of wind sites and maintenance planning or to incorporate portfolio effects. Klessmann et al. (2008) on the other hand point out that market exposure increases risk for investors, which leads to a higher required level of financial support in order to stimulate investments. The impact of renewable energy subsidies on the spatial allocation of wind power investments is explicitly studied in Schmidt et al. (2013) and Pechan (2017). Schmidt

5. Note that investment based tax credits or low interest loans are equivalent to direct capacity payments as they reduce the net present value of investment costs. 
et al. (2013) analyze the spatial distribution of wind turbines under a feed-in premium and a feed-in tariff scheme based on an empirical model for Austria. They find that the feed-in premium system leads to substantially higher diversification of locations for wind power generation. Pechan (2017) shows in a numerical model, that a feed-in premium system combined with nodal pricing leads to a system friendly allocation of wind power if existing transmission lines are congested. All mentioned papers do not consider capacity payments or the required grid extensions to integrate the wind power capacity into the electricity system.

The second relevant literature stream is focused on the coordination problem between transmission and generation investment in liberalized power markets and the effects of anticipatory transmission investment. Sauma and Oren (2006) and Pozo et al. (2013) show that a proactive transmission planner can induce generation companies to invest in a more socially efficient manner by anticipating investments in generation capacity. Höffler and Wambach (2013) show that generation investment can lead to overinvestment or underinvestment in the electricity grid when private investors do not take the costs and benefits of network extensions into account. They also show that a capacity market can incentivize private investors to make socially efficient locational choices. The implications of renewable subsidies on the coordination problem are not part of the mentioned studies. The interactions of renewable portfolio standards and transmission planning are examined in Munoz et al. (2013). They show that ignoring the lumpy nature of transmission investment when planning the necessary grid extension for the integration of renewable energies can lead to significant inefficiencies in network investments. The effect of different support schemes is not part of the analysis.

In summary the contribution of the paper is threefold. First, the locational choice of renewable energy investors under different support schemes is analyzed in a theoretical framework. Second, interactions between the renewable support scheme and grid investments are analyzed. Third, anticipatory transmission investment is analyzed focusing explicitly on the coordination of subsidized renewable investment and grid investment. Therefore the paper intends to close the gap between the literature streams on support schemes for renewable energy and on the coordination problem between generation investment and grid investment in unbundled electricity systems.

The remainder of the paper is structured as follows. Section 2 introduces the model and analyzes the efficient allocation of renewable generation capacities as well as the investment problems for renewable energy investors and grid investments. Building on that, welfare effects are analyzed and a simple numerical example is presented. Section 3 introduces asymmetric grid investment costs, imperfect regulation of the transmission operator and network charges for renewable producers as model extensions. Section 4 concludes.

\section{THE MODEL}

We consider a model with three nodes $D, H$ and $L$, which are not connected initially. At node $D$ electricity consumption is located with an inelastic demand of quantity $d$. Additionally, two conventional generation technologies are located at node $D$. A cheap base-load technology with marginal generation $\operatorname{costs} c_{1}$ and limited generation capacity $\bar{q}$ as well as a peak-load technology with unlimited generation capacity but higher marginal generation costs $c_{2}>c_{1}$. It is assumed that a political target to reach a generation capacity $K_{T}<d$ based on renewable energy sources is in place. ${ }^{6}$

6. In practice political renewable targets are defined in terms of capacity or electricity generation. However, even in countries with generation targets, for example Germany, the monitoring of target achievement is often undertaken based on installed capacity. See International Renewable Energy Agency (2015) for a discussion. 
Figure 1: Network configuration (a) and supply curve of conventional generation (b)

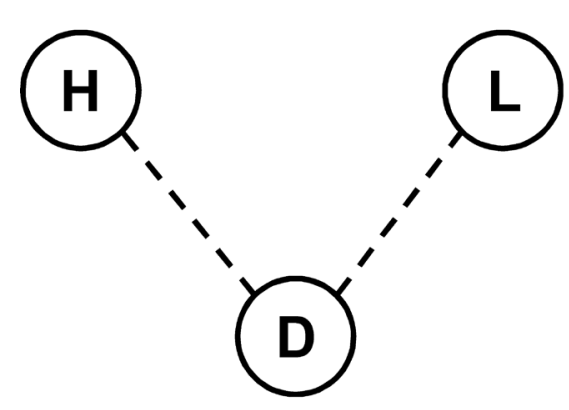

(a)

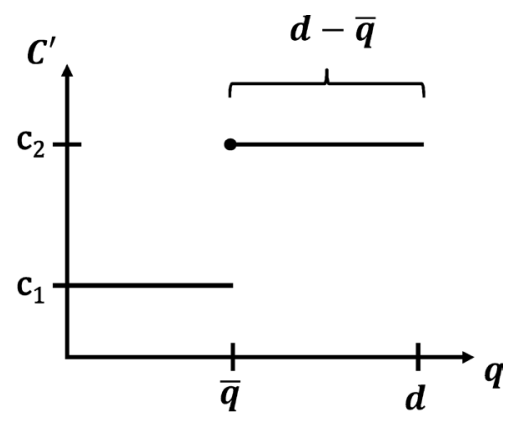

(b)

Additionally it is assumed that $\bar{q} \geq d / 2 .^{7}$ The renewable target can be reached by investment into wind generation capacity at nodes $H$ and $L$. Investment costs for one unit of capacity are $I^{W}{ }^{8}$ Marginal costs of wind power production are assumed to be zero. Investments are subsidized either by a feed-in tariff system, feed-in premium system or direct capacity payments. To connect the wind power plants at nodes $H$ and $L$ to the demand node $D$ transmission lines have to be built. Investment into transmission requires investment costs $I^{G}$ and is modeled as a binary decision. Hence, once an investment is made, the transmission capacity is unlimited, which represents the lumpy character of transmission investments. ${ }^{9}$

The model configuration is depicted in Figure 1. Figure 1(a) shows the nodes of the model as well as the potential network connections represented by dashed lines. Figure 1(b) shows the supply curve of conventional generation with different marginal generation costs for the base-load and peak-load technology. The depicted quantity $(d-\bar{q})$ represents the amount of electricity that has to be generated with the costly peak-load technology if no wind power generation is present.

Wind generation at nodes $H$ and $L$ is stochastic with three possible states $h, l$ and $h l$, which occur with probabilities $\rho_{h}, \rho_{l}$ and $\rho_{h l}\left(\rho_{h}+\rho_{l}+\rho_{h l}=1\right)$. In states $h$ and $l$ only wind power plants at node $H$ or $L$ produce electricity whereas in state $h l$ wind power is produced at both nodes. ${ }^{10}$ Additionally it is assumed that $\rho_{h}>\rho_{l}$ which means that the expected wind output is higher at node $H$.

The described configuration accounts for two important properties of wind power generation. The first property is a substantial variation of expected electricity generation between different wind locations. The second property is that wind power generation is imperfectly correlated between different locations as a result of the spatial variation in weather conditions. In the model the correlation between the locations $H$ and $L$ can be modified by the value of $\rho_{h l}$. If $\rho_{h l}$ equals zero wind output is perfectly negative correlated between the two nodes. The higher $\rho_{h l}$ the higher is the

7. This assumption is made in order to focus the analysis on the question if and under which conditions the wind locations $H$ and $L$ are developed. Extending the analysis for $\bar{q}<\frac{d}{2}$ is straight forward but requires additional case distinctions which do not provide substantial insights regarding the central questions of the study.

8. The capacity factor is assumed to be one, which means that the full installed capacity is available for production if wind is present. In reality this factor is smaller than one and depends on the wind speed as well as the technical properties of the wind power plant.

9. Lumpiness describes the fact that transmission capacity is increased in discrete steps as a result of strong economies of scale, see for example Joskow and Tirole (2005).

10. A fourth state in which none of the locations produce wind power is not included for reasons of simplification. Such a state could however be included without changing the results of the analysis. 
correlation between nodes and the lower is the probability that only one of the locations produces wind power. ${ }^{11}$ Only two wind locations are chosen for the analysis in order to simplify the model. However, adding additional locations would not change the implications of the paper. Also, in practice there are typically only a limited number of suited geographical areas which have substantially differing wind properties within a country. ${ }^{12}$

The dynamic setting of the model consists of three stages: Transmission investment, wind power investment and cost minimal dispatch. The dispatch takes place in the last stage of the model after the stochastic wind generation is realized. Investment decisions on the other hand are based on the expected wind output. To assess the effects of uncoordinated generation and grid investments as well as anticipatory and reactive behavior of the transmission operator (TSO), three different model configurations are considered:

(i) Central planner: The central planner jointly invests into grid and wind power capacities in order to minimize total expected system costs. This model setting represents a vertically integrated electricity system and is considered as a first-best benchmark.

(ii) Reactive TSO: Under reactive transmission investment, revenue maximizing investment into wind power with feed-in tariff (FIT), feed-in premium (FIP) or capacity payments (CAP) happens in the first stage followed by transmission investment in the second stage. It is assumed that the TSO has to comply with the renewable target and is therefore obliged to connect all wind power investments from the first stage. Consequently, the TSO solely reacts to wind power investments from the first stage.

(iii) Anticipatory TSO: Under anticipatory transmission investment the transmission operator acts first and builds transmission lines to integrate wind power capacities according to the capacity target $K_{T}$. In the second stage, wind power investors build generation capacities given the network infrastructure from the first stage. As an additional steering instrument the TSO is able to limit transfer capacities of transmission lines. Hence, the TSO can actively influence wind power investments.

In all settings perfect information and risk neutral behavior of investors is assumed. Free market entry is assumed for renewable investors, which means that no market power can be exercised. In the basic model, the TSO is assumed to behave benevolently as a result of perfect regulation. Imperfect regulation is discussed as a model extension in Section 3. Figure 2 illustrates the dynamics of the model for all considered cases graphically.

The model is solved by backward induction. Therefore the dispatch problem, which is common for all described model settings, is solved first, followed by the renewable and transmission investment problems.

11. The described representation of stochastic wind power generation is similar to Ambec and Crampes (2012) and Milstein and Tishler (2015). Both papers analyze interactions between investments into dispatchable and intermittent sources of electricity generation. A disadvantage of this simple model of stochasticity is that the variance of wind generation can not be changed independently of the expected wind generation. Note that the model considers only one period of wind generation. However an extension with multiple periods, e.g. for every day in a year, can be realized by repetition, as done for example in Milstein and Tishler (2015).

12. See for example Madrigal and Stoft (2012) for a geographical depiction of wind regions in several relevant countries. 


\section{Figure 2: Dynamic model settings}

$t=1$

$t=2$

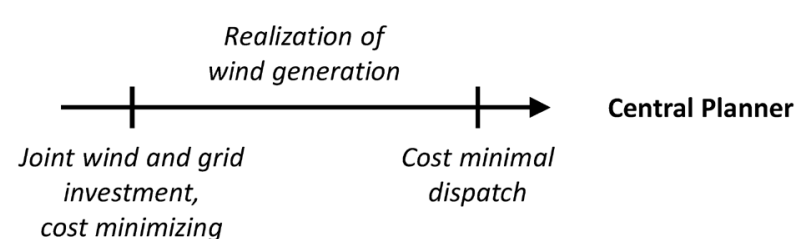

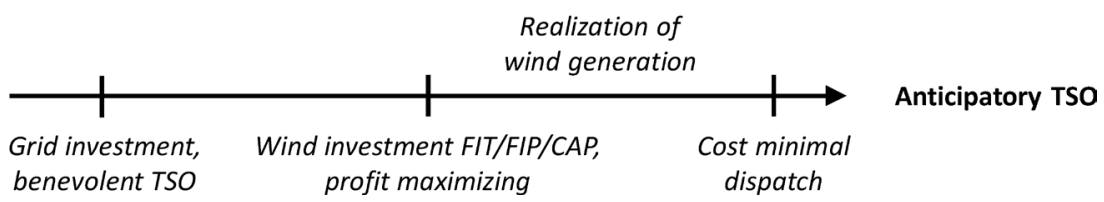

\subsection{The dispatch problem}

In the third stage of the model, the dispatch costs $C_{D}$ are minimized based on investments in the prior stages and the realization of wind power generation. Consequently, conventional generation capacities at node $D$ are utilized to meet the electricity demand that can not be covered by the wind power generation delivered to node $D$ given the grid and wind power investments from the first and second stage. As a result, renewable generation $R$ is exogenous in the third stage and conventional generation $q$ is dispatched according to the problem formulated in Equations (1) and (2). ${ }^{13}$

$$
\begin{aligned}
\min _{q} C_{D} & =\left\{\begin{array}{cc}
q c_{1} & \text { if } q<\bar{q} \\
\bar{q} c_{1}+(q-\bar{q}) c_{2} & \text { if } q \geq \bar{q}
\end{array}\right. \\
\text { s.t. } d & =q+R
\end{aligned}
$$

The cost function (1a) represents the two available conventional generation technologies with marginal generation cost equal to $c_{1}$ as long as the conventional generation $q$ is smaller than the maximum capacity $\bar{q}$ of the base-load technology. If conventional generation exceeds $\bar{q}$ the marginal generation costs $c_{1}$ of the peak-load technology incur. Equation (1b) is the balance constraint which $\mathcal{L}=C_{D}+\lambda(d-q-R)$ equal to zero yields the following expressions:
ensures that electricity demand $d$ is met. Setting the partial derivatives $\frac{\partial \mathcal{L}}{\partial q}$ and $\frac{\partial \mathcal{L}}{\partial \lambda}$ of the lagrangian

$$
\begin{aligned}
& \lambda= \begin{cases}c_{1} & \text { if } q<\bar{q} \\
c_{2} & \text { if } q \geq \bar{q}\end{cases} \\
& q=d-R
\end{aligned}
$$

13. Curtailment of wind power generation is not considered. 
Equation (2a) expresses that the market price equals marginal generation costs. Equation (2b) states that conventional generation equals residual demand. These expressions are a stylized representation of the merit order effect as the market price for electricity drops from $c_{2}$ to $c_{1}$ if the wind generation delivered to demand node $D$ is higher than $(d-\bar{q}) \cdot{ }^{14}$

Because of the stochastic nature of wind generation, the investment problems are based on the expected dispatch outcome which depends on the expected value of wind power generation $\mathbf{E}(R)$ delivered to node $D$ :

$$
\begin{aligned}
\mathbf{E}(R) & =\rho_{h} K_{H}+\rho_{l} K_{L}+\rho_{h l}\left(K_{H}+K_{L}\right) \\
K_{H} & =\operatorname{Cap}_{H} L_{H} \\
K_{L} & =\operatorname{Cap}_{L} L_{L} \\
L_{L}, L_{H} & \in\{1,0\}
\end{aligned}
$$

$\mathbf{E}(R)$ is a function of the installed wind power capacity at nodes $H$ and $L$ and the probability that these capacities will produce electricity. Additionally, a transmission line between the demand node and the wind site has to be in place in order to use the wind power production to meet electricity demand. This is expressed in Equations (3b) and (3c) by the product of installed capacities Cap $_{H}$, $\mathrm{Cap}_{L}$ and the binary variables $L_{H}, L_{L}$ which indicate if a connection between the wind locations and the demand node is in place.

Because of the piecewise linear form of the cost function of conventional power generation, several cases of connected wind power capacity have to be distinguished in order to determine the expected dispatch outcome. Decisive for the case distinction is if the conventional peak load technology is crowded out of the market because of the realized wind generation in each possible state. Based on this logic, five cases can be distinguished as indicated in Equation (4). In the first case the peak load technology is displaced in every possible outcome. In the second and third case the peak load technology is not displaced if states $l$ or $h$ respectively are realized. In the fourth case the peak load technology is only displaced if state $h l$ is realized and in the fifth case the peak load technology is not displaced in all outcomes. The aggregated connected wind power capacity at both wind locations is represented by $K_{A}=K_{H}+K_{L}$.

$$
\mathbf{E}\left(C_{D}\right)=\left\{\begin{array}{rr}
c_{1}\left(d-\rho_{l} K_{L}-\rho_{h} K_{H}-\rho_{h l} K_{A}\right) & \\
& \text { if } K_{H}, K_{L}>d-\bar{q} \\
c_{1}\left(\rho_{l} \bar{q}+\rho_{h}\left(d-K_{H}\right)+\rho_{h l}\left(d-K_{A}\right)\right)+c_{2} \rho_{l}\left(d-\bar{q}-K_{L}\right) & \text { if } K_{H}>d-\bar{q}, K_{L} \leq d-\bar{q} \\
c_{1}\left(\rho_{h} \bar{q}+\rho_{l}\left(d-K_{L}\right)+\rho_{h l}\left(d-K_{A}\right)\right)+c_{2} \rho_{h}\left(d-\bar{q}-K_{H}\right) \\
& \text { if } K_{H} \leq d-\bar{q}, K_{L}>d-\bar{q} \\
c_{1}\left(\left(\rho_{h}+\rho_{l}\right) \bar{q}+\rho_{h l}\left(d-K_{A}\right)\right)+ & c_{2}\left(\left(\rho_{h}+\rho_{l}\right)(d-\bar{q})-\rho_{h} K_{H}-\rho_{l} K_{L}\right) \\
& \text { if } K_{H}, K_{L} \leq d-\bar{q}, K_{A}>d-\bar{q} \\
c_{1} \bar{q}+c_{2}\left(d-\bar{q}-\rho_{l} K_{L}-\rho_{h} K_{H}-\right. & \left.\rho_{h l} K_{A}\right) \\
& \text { if } K_{H}, K_{L} \leq d-\bar{q}, K_{A} \leq d-\bar{q}
\end{array}\right.
$$

14. The merit order effect describes the price depressing impact of renewable electricity generation with marginal generation costs close to zero on wholesale prices. See Würzburg et al. (2013) for a review of empirical studies which analyze this effect for different European markets. 
Analogously the expected market price $\mathbf{E}(\lambda)$ can be expressed by the marginal generation $\operatorname{costs} c_{1}$ and $c_{2}$ weighted with the probability that each technology sets the market price in the five distinguished cases.

$$
\mathbf{E}(\lambda)= \begin{cases}c_{1} & \text { if } K_{H}, K_{L}>d-\bar{q} \\ c_{1}\left(1-\rho_{h}\right)+c_{2} \rho_{h} & \text { if } K_{H}>d-\bar{q}, K_{L} \leq d-\bar{q} \\ c_{1}\left(1-\rho_{l}\right)+c_{2} \rho_{l} & \text { if } K_{H} \leq d-\bar{q}, K_{L}>d-\bar{q} \\ c_{1} \rho_{h l}+c_{2}\left(1-\rho_{h l}\right) & \text { if } K_{H}, K_{L} \leq d-\bar{q}, K_{A}>d-\bar{q} \\ c_{2} & \text { if } K_{H}, K_{L} \leq d-\bar{q}, K_{A} \leq d-\bar{q}\end{cases}
$$

Equations (4) and (5) show that the expected dispatch costs as well as the expected electricity price decrease with increasing connected wind power capacity as a result of the merit order effect. Additionally the effect of imperfect correlation of wind generation between the locations is apparent because the conventional peak load technology is only displaced completely in all states if the installed wind capacity at both locations exceeds $(d-\bar{q})$.

\subsection{The central planner investment problem}

The central planner jointly invests into wind power generation capacity and transmission lines in order to meet the wind power capacity target $K_{T}$. The objective of the central planner is to minimize total system costs which include expected dispatch costs and investment costs. With specific investment costs for wind power $I^{W}$ and grid investment costs $I^{G}$ this translates into the following minimization problem:

$$
\begin{aligned}
\min _{\operatorname{Cap}_{H}, \operatorname{Cap}_{L}, L_{H}, L_{L}} C_{\text {Total }} & =\mathbf{E}\left(C_{D}\right)+I^{W}\left(\operatorname{Cap}_{H}+\operatorname{Cap}_{L}\right)+I^{G}\left(L_{H}+L_{L}\right) \\
\text { s.t. } K_{T} & =\operatorname{Cap}_{H} L_{H}+\operatorname{Cap}_{L} L_{L} \\
L_{L}, L_{H} & \in\{1,0\}
\end{aligned}
$$

Because of the binary character of grid investments, problem (6) can be solved by analyzing optimal wind power investment and the corresponding system costs for all possible network configurations. Consequently, total investment costs with one wind location and both wind locations connected to the demand node $D$ have to be compared. Based on this comparison the following proposition can be derived:

Proposition 1. The central planner diversifies wind locations if the reduction of expected dispatch costs outweighs the required additional grid investment costs. Depending on the target for wind power capacity, two cases can be distinguished:

(i) For $K_{T} \leq d-\bar{q}$ diversification is never optimal

(ii) For $K_{T}>d-\bar{q}$ diversification is optimal if and only if $\left(c_{2} \rho_{l}-c_{1} \rho_{h}\right)\left(K_{T}-(d-\bar{q})\right)>I^{G}$

Proof. See Appendix A.1.

Proposition 1 points out that the central planner faces a trade off between reducing expected dispatch cost due to diversification of wind sites and the grid investment costs, which are required to connect the additional location. For renewable targets below $(d-\bar{q})$ it is never optimal 
Figure 3: Expected dispatch costs in the central planner problem

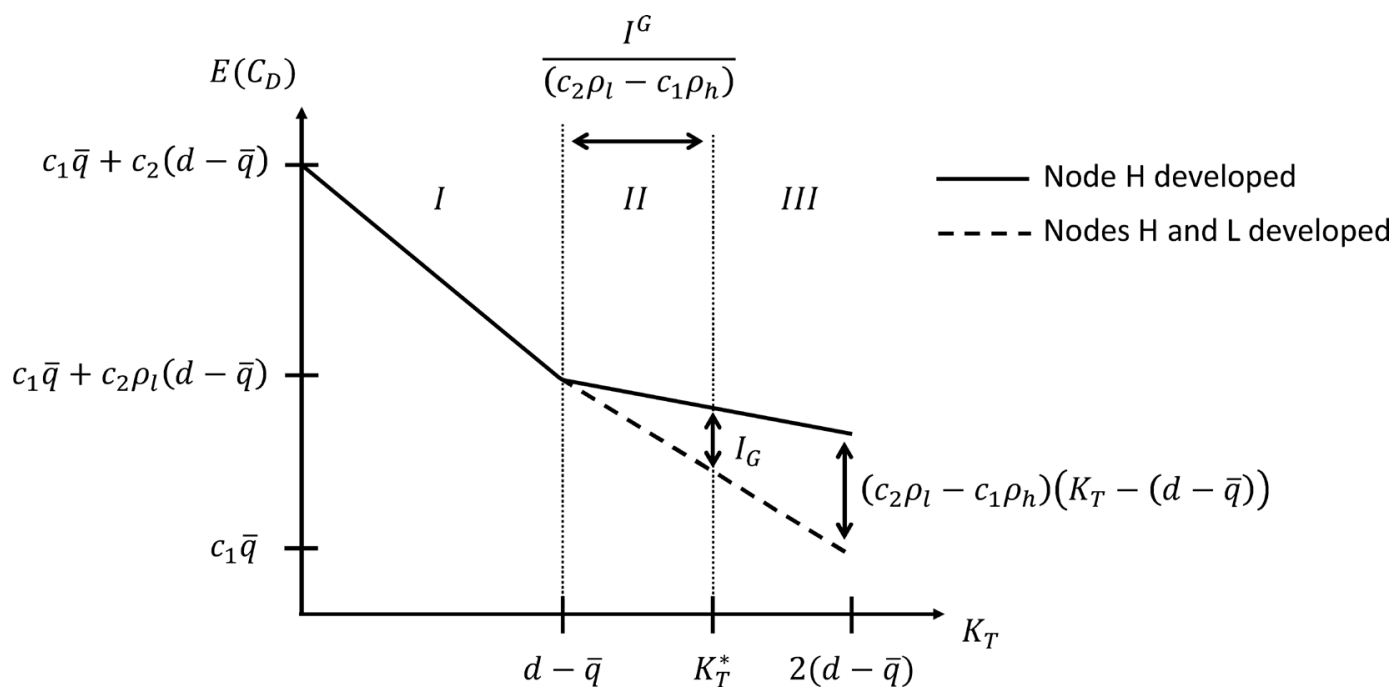

to develop both locations because there is no benefit of diversification as long as all the produced wind power at the better wind location $H$ replaces costly conventional peak-load generation.

For renewable targets above $(d-\bar{q})$ the central planner always builds wind power capacity of $(d-\bar{q})$ at node $H$. The remaining quantity $K_{T}-(d-\bar{q})$ can either be also built at node $H$ to replace base-load generation with probability $\rho_{h}+\rho_{h l}$ or alternatively at node $L$ to replace peakload generation with probability $\rho_{l}$ and base-load generation with probability $\rho_{h l}$. Consequently, a prerequisite for developing the low wind location $L$ is that the cost difference between peak-load and base-load generation outweighs the difference in expected wind output between nodes $H$ and $L$. Formally this means that $c_{1} \rho_{h}<c_{2} \rho_{l}$ must hold. If this condition is true, the central planner chooses to build a capacity of $(d-\bar{q})$ at the better wind location $H$ and the remaining $K_{T}-(d-\bar{q})$ at the low wind location $L$ if the achievable reduction in expected dispatch costs outweighs the required investment costs for the additional transmission line to node $L$. For $K_{T}>d-\bar{q}$ the potential benefits of developing the second wind location increase with the renewable target. For $K_{T}=2(d-\bar{q})$ the maximum potential benefit of diversification is reached, which means that the central planner never chooses to develop both wind locations if the condition $\left(c_{2} \rho_{l}-c_{1} \rho_{h}\right)(d-\bar{q})>I^{G}$ is not satisfied.

The described result of Proposition 1 is shown graphically in Figure $3 .{ }^{15}$ Expected dispatch costs when only node $H$ is connected are depicted by the solid line. The reduction of expected dispatch cost for one additional unit of wind power capacity is $c_{2}\left(\rho_{h}+\rho_{h l}\right)$ for $K_{T} \leq(d-\bar{q})$ and $c_{1}\left(\rho_{h}+\rho_{h l}\right)$ for $K_{T}>(d-\bar{q})$. Expected dispatch costs with nodes $H$ and $L$ connected are depicted by the dashed line. For $K_{T}>(d-\bar{q})$ the reduction of expected dispatch costs is $c_{2} \rho_{l}+c_{1} \rho_{h l}$ for every additional unit of wind power generation. The difference between the solid and dashed lines corresponds to the reduction in dispatch costs due to diversification of wind locations. Developing the low wind location $L$ is socially beneficial if this cost reduction exceeds the additional grid investment costs $I^{G}$. As indicated in Figure 3 this is true for capacity targets for renewable energy above a critical level $K_{T}^{*} \cdot{ }^{16}$ 
As a result three areas can be distinguished in Figure 3. In area $I$, investment only at the high wind location is always preferable. In area $I I$, developing the low wind location $L$ is not socially beneficial because the achievable reduction in expected dispatch costs does not outweigh grid investment costs. In area $I I I$, developing the low wind location is efficient. The relative size of area II increases with $I^{G}$ and decreases with $\left(c_{2} \rho_{l}-c_{1} \rho_{h}\right)$. If $\left(c_{2} \rho_{l}-c_{1} \rho_{h}\right)(d-\bar{q}) \leq I^{G}$ area III does not exist and it is never optimal to develop both locations.

An important result of Proposition 1 is that the benefit of wind location diversification increases with $\rho_{l}, c_{2}$ and $\bar{q}$, while it decreases with $\rho_{h}$ and $c_{1}$. Consequently, a lower quality difference between the high wind location $H$ and the low wind location $L$ as well as a steeper merit order of the conventional power plant fleet increases the benefit of developing both wind locations. Additionally, a higher availability of cheap base load technology increases the achievable reduction in expected dispatch costs because less peak load generation can be displaced by wind investments at the better wind location. A higher correlation between wind generation at both wind locations on the other hand decreases the benefit of diversifying wind locations for a given probability $\rho_{h}$. The described impact of the correlation between wind generation at nodes $H$ and $L$ shows that not only the total wind generation but also the difference in generation patterns over time is decisive for optimal wind power investment. It can be socially efficient to develop the location with lower total wind generation because there are situations where the better wind location does not produce electricity while the low wind location does. This is precisely the potential benefit of diversification described in Proposition 1.

\subsection{The renewable energy investment problem}

In this section the investment problem for wind power producers in an unbundled electricity system is solved for a feed-in tariff scheme, a feed-in premium system and direct capacity payments. Based on these results the effects of reactive behavior of the transmission operator can be assessed. The central planner problem from the previous section serves as a first-best benchmark to identify inefficiencies.

\subsubsection{Feed-in tariff}

Under a feed-in tariff scheme, wind power investors receive a fixed payment for every produced kilowatt hour of electrical energy. Consequently, each revenue maximizing investor $i$ faces the optimization problem expressed in Equations (7a) and (7b). E $\left(\pi_{i}\right)$ represents the expected revenue and FIT the fixed feed-in tariff.

$$
\begin{gathered}
\max _{\operatorname{Cap}_{L, i}, C a p_{H, i}} \mathbf{E}\left(\pi_{i}\right)=F I T * \mathbf{E}\left(R_{i}\right)-I^{W}\left(\operatorname{Cap}_{L, i}+\operatorname{Cap}_{H, i}\right) \\
\text { s.t. } K_{T}=\sum_{i} \operatorname{Cap}_{H, i} L_{H}+\sum_{i} \operatorname{Cap}_{L, i} L_{L}
\end{gathered}
$$

FIT is assumed to be set by the regulator to a level which guarantees non-negative expected profits for all required investments to meet the capacity target $K_{T}$. Wind power investors maximize the expected revenue by choosing wind capacities with the highest expected wind generation $\mathbf{E}\left(R_{i}\right)$ for a given FIT. Hence, investors never choose to build capacity at the low wind location $L$ under a feed-in tariff scheme because the market value of the produced electricity is not internalized and $\rho_{h}>\rho_{l}$. As a result there is underdiversification of wind locations compared to the first-best solution 
of the central planner because even if developing both locations is socially beneficial investors do not invest at node $L$. Consequently, inefficiencies can arise in an unbundled system with a feed-in tariff system if the transmission operator behaves reactively and builds the grid according to the decisions of renewable investors. The results are summarized in the following proposition:

Proposition 2a. In a feed-in tariff system investors always prefer the location with the highest expected wind generation because the market value of electricity is not internalized. As a result, there is underdiversification of wind locations compared to the first-best solution. Overdiversification of wind locations is not possible.

Proof. See Appendix A.1.

\subsubsection{Feed-in premium}

In a feed-in premium system, renewable investors sell the produced electrical energy in the spot market and receive an additional fixed premium payment. Hence, investors have to take into account not only the expected wind generation but also the expected market price as well as the correlation between market price and wind generation. Equations (8a) and (8b) show the resulting maximization problem for each renewable investor $i$. The covariance term enters in Equation (8a) because of the expected market revenue $\mathbf{E}\left(\lambda * R_{i}\right)=\mathbf{E}(\lambda) * \mathbf{E}\left(R_{i}\right)+\operatorname{Cov}\left(\lambda, R_{i}\right) . F I P$ represents the fixed premium payment. Again it is assumed, that FIP is set to a level that ensures the realization of the capacity target $K_{T}$ with non-negative expected profits.

$$
\begin{gathered}
\max _{\operatorname{Cap}_{L, i}, \operatorname{Cap}_{H, i}} \mathbf{E}\left(\pi_{i}\right)=\mathbf{E}(\lambda) * \mathbf{E}\left(R_{i}\right)+\operatorname{Cov}\left(\lambda, R_{i}\right)+F I P^{*} \mathbf{E}\left(R_{i}\right)-I^{W}\left(\operatorname{Cap}_{L, i}+\operatorname{Cap}_{H, i}\right) \\
\text { s.t. } K_{T}=\sum_{i} \operatorname{Cap}_{H, i} L_{H}+\sum_{i} \operatorname{Cap}_{L, i} L_{L}
\end{gathered}
$$

As indicated by Equation (8a), investors receive two different revenue streams in a feed-in premium system. The revenue stream from fixed premium payments is only determined by the expected wind power generation at a given location. The revenue stream from spot market sales however, additionally depends on the realized market price. For low renewable targets $K_{T} \leq d-\bar{q}$, the market price equals $c_{2}$ for all possible states $h, l$ and $h l$. Consequently, investment is always more profitable at the location with the highest expected wind generation as both revenue streams are higher for investments at node $H$. For investment levels above $(d-\bar{q})$ it is always preferable to install a capacity of at least $(d-\bar{q})$ at node $H$ because of the higher expected wind output. Above that level an additional unit of wind power capacity at node $H$ earns less revenue in the spot market because prices are depressed to $c_{1}$ if states $h$ or $h l$ are realized. However, investors can instead choose to invest at the second wind location, where they still earn the higher market price $c_{2}$ when state $l$ is realized and $c_{1}$ in state $h l$. As a result, the expected revenue from spot market sales is higher at node $L$ if $c_{2} \rho_{l}>c_{1} \rho_{h}$. The premium payment on the other hand depends only on the expected wind power generation and is always higher at node $H$. Consequently, investors choose to develop the low wind location if the expected additional spot market revenue at node $L$ outweighs the lower expected premium payments:

$$
c_{2} \rho_{l}-c_{1} \rho_{h}>\left(\rho_{h}-\rho_{l}\right) F I P
$$

Equation (9) implies that the profitability of investing at the low wind location increases with the difference between $c_{2}$ and $c_{1}$. Hence, comparable to the central planner problem the steepness of the 
merit order of the conventional power plant fleet is decisive for the profitability of diversifying wind locations. Additionally it can be seen that a higher feed-in premium decreases the profitability of investing at location $L$, because the share of revenue from the fixed premium payments in relation to the revenue generated from spot market sales increases. A higher quality of the low wind location $\rho_{l}$ increases the profitability of investments at node $L$ because the expected spot market revenue at the low wind location increases and the difference in fixed premium payments compared to the high wind location decreases. Also, for a given probability $\rho_{h}$, a higher correlation between generation at the two wind locations decreases the profitability of diversifying wind locations.

The discussed results show that the grid investment costs which are required to connect the second wind location to node $D$ are external costs for the wind power investor and are therefore not considered in the decision. Consequently, inefficiencies arise in a feed-in premium system if transmission investment follows wind power investors and the optimality conditions in Proposition 1 are inconsistent with the behavior of wind power investors formulated in Equation (18). Proposition 2 summarizes the results for wind power investments in a feed-in premium subsidy scheme.

Proposition $2 \mathbf{b}$. In a feed-in premium system investors develop both locations if the expected additional spot market revenue outweighs the lower premium payments. Investors underdiversify locations if the revenue stream from premium payments dominates. If the revenue stream from market participation dominates, investors overdiversify locations compared to the first best solution.

Proof. See Appendix A.1.

To further analyze the implications of Proposition $2 \mathrm{~b}$ it is assumed that the feed-in premium equals the efficient level, that sets marginal revenue of wind power investment equal to zero. ${ }^{17}$ Plugging this value of FIP into Equation (9) yields the following condition for the development of the low wind location $L$ under a feed-in premium scheme with $K_{T}>(d-\bar{q})$ :

$$
I^{W}<\frac{\left(c_{2}-c_{1}\right)\left(\rho_{l}-\rho_{l}^{2}\right)}{\rho_{h}-\rho_{l}}
$$

As mentioned above the decision on diversification of wind locations in a feed-in premium scheme depends on the investment costs for wind power plants which determine the required level of subsidies and subsequently the share of revenue from fixed premium payments. Consequently, diversifying wind locations becomes more attractive as the technological maturity of wind power plants increases and less premium payments are necessary to cover investment costs as indicated by the left hand side of Equation (10). The right hand side is determined by the steepness of the conventional merit order and the expected wind generation at nodes $H$ and $L$. It can be seen that a steeper merit order increases the profitability of investing at the low wind location. Additionally, an increase in $\rho_{l}$ makes investments at node $L$ more attractive as the right hand side of Equation (10) is strictly increasing in $\rho_{l}{ }^{18}$

\subsubsection{Capacity payment}

In a subsidy system with direct capacity payments, wind power investors generate revenue only in the spot market. Additionally they receive a fixed subsidy payment $S U B$ for every unit of

17. The mathematical expression for the marginal revenue of wind power investment at nodes $H$ and $L$ is provided in Equations (17) and (18) in Appendix A.1.

18. Note that $0<\rho_{l}<0.5$ because of $\rho_{h}>\rho_{l}$ so $\rho_{l}-\rho_{l}^{2}$ is strictly increasing in $\rho_{l}$. 
capacity they build, which is equivalent to a reduction of the investment costs. The resulting optimization problem is expressed in Equation (11):

$$
\max _{\operatorname{Cap}_{L, i}, C a p_{H, i}} \mathbf{E}\left(\pi_{i}\right)=\mathbf{E}(\lambda) * \mathbf{E}\left(R_{i}\right)+\operatorname{Cov}\left(\lambda, R_{i}\right)-\left(I^{W}-S U B\right)\left(\operatorname{Cap}_{L, i}+\operatorname{Cap}_{H, i}\right)
$$

With capacity payments renewable investors maximize spot market revenue. For low renewable targets $K_{T} \leq d-\bar{q}$ the expected spot market revenue is higher at location $H$ because of the higher expected wind generation. Once the installed capacity at the high wind location is equal to $(d-\bar{q})$ an additional unit of wind capacity at node $H$ generates expected spot market revenue of $c_{1}\left(\rho_{h}+\rho_{h l}\right)$ because the conventional peak-load technology gets crowded out of the market in states $h$ and $h l$. Investments at node $L$ on the other hand generate expected spot market revenue of $c_{2} \rho_{l}+c_{1} \rho_{h l}$. Consequently, investors always choose to invest at node $L$ if the following condition is true:

$$
c_{2} \rho_{l}>c_{1} \rho_{h}
$$

Compared to the feed-in premium system, the condition for developing the low wind location is less restrictive. By comparing the results with the central planner solution it can additionally be derived that underdiversification of wind locations is not possible in a subsidy system with capacity payments. ${ }^{19}$ Instead, there is overdiversification of wind locations as the market value of wind energy is fully internalized while grid investment costs are external. Proposition $2 \mathrm{c}$ summarizes the findings.

Proposition 2c. In a system with direct capacity payments investors choose locations where the highest expected spot market revenue can be generated. As a result, there is overdiversiversification of wind locations compared to the first-best solution. Underdiversification of wind locations is not possible.

Proof. See Appendix A.1.

\subsection{Anticipatory transmission investment}

The results of the previous section show that in an unbundled electricity system inefficiencies can arise due to uncoordinated investment into wind power capacity and into the grid under all considered subsidy schemes. The possible inefficiencies are underdiversification of wind locations, which means that potential reductions in total system costs due to development of additional locations are not used, and overdiversification of wind locations, which means that wind power investments enforce inefficient grid extensions. This section analyzes if a proactive transmission operator can prevent these inefficiencies by anticipating decisions of wind power investors.

It is assumed that the transmission operator is benevolent and minimizes total system costs. Additionally it is assumed that the transmission operator has perfect information and knows all relevant parameters of the electricity system. Consequently, the transmission operator decides whether to build transmission lines to nodes $H$ and $L$ based on the grid investment costs and the expected dispatch costs, which result from private wind power investments in different network configurations. The objective function of the transmission operator is the same as in the central planner problem because of the assumed benevolence. The difference to problem (6) is that the transmission operator can not directly influence installed wind power capacities.

19. According to the second part of Proposition $1 c_{2} \rho_{l}>c_{1} \rho_{h}$ is a necessary but not sufficient condition for the optimality of developing the low wind location $L$. However, in a subsidy system with capacity payments investors always choose to develop location $L$ if this condition is true. 
To enable the transmission operator to prevent underdiversification of wind locations it is assumed that he is able to limit the transfer capacity of a transmission line once it is build. For reasons of simplification only the limitation of transfer capacity to the high wind location $H$ is considered ${ }^{20}$ Based on these assumptions the optimization problem of the transmission operator is formulated in Equations (13a) to (13c). $\overline{L_{H}}$ represents the limited transfer capacity to node $H$. $\mathbf{E}\left(C_{D}\left(\cdot, \overline{L_{H}}\right)\right)$ expresses that the expected dispatch costs are now also influenced by the limited transfer capacity. ${ }^{21}$

$$
\begin{aligned}
\min _{L_{H}, L_{L}, \bar{L}_{H}} C_{\text {Total }} & =\mathbf{E}\left(C_{D}\left(\cdot \overline{L_{H}}\right)\right)+I^{W}\left(\operatorname{Cap}_{H}+\operatorname{Cap}_{L}\right)+I^{G}\left(L_{H}+L_{L}\right) \\
\text { s.t. } K_{T} & =\operatorname{Cap}_{H} L_{H}+\operatorname{Cap}_{L} L_{L} \\
L_{L}, L_{H} & \in\{1,0\}
\end{aligned}
$$

As discussed in the previous section two types of inefficiencies can arise depending on the subsidy scheme for renewable energy, namely underdiversification and overdiversification of wind locations. As the transmission operator has perfect information over the electricity system he can anticipate wind power investments and the resulting inefficiencies. If wind power investors develop too many wind locations, which is possible in a subsidy system with direct capacity payments or in a feed in premium system under the conditions explained in Sections 2.3.2 and 2.3.3, the transmission operator can refuse to connect the low wind location $L$ to the demand node $D$. This prevents overdiversification as investors have no incentive to invest at location $L$ if they know that no transmission line will be built and they can not generate any revenue at node $L$. If wind power producers invest only at the high wind location $H$ despite potential social benefits of developing both wind locations, the transmission operator can choose to build both transmission lines and force investors to move to location $L$ by limiting transfer capacity to node $H$. This prevents underdiversification because additional investments above the capacity limit will not be able to generate positive expected profits. The optimal capacity limit is equal to $(d-\bar{q})$, which is the social optimal investment level at node $H$ if diversification of wind locations is beneficial. Proposition 4 summarizes the results.

\section{Proposition 3.}

(i). If the subsidy scheme for wind power investment incentivizes overdiversification, the transmission operator chooses not to connect the inferior wind location $L$.

(ii). If the subsidy scheme for wind power investment incentivizes underdiversification, the transmission operator connects both locations and limits the transfer capacity to the superior wind location to $(d-\bar{q})$, which forces investors to develop both wind locations.

Proof. See Appendix A.1.

\subsection{Welfare effects and policy implications}

Based on the findings described in Propositions 1 to 3, this section discusses welfare effects and derives policy implications. Figure 4 summarizes the previous results graphically. The depiction

20. Including the option to limit transfer capacity to node $L$ into the problem would however not change the results 21. The "." represents the remaining factors as discussed in Section 2.1. 
Figure 4: Overview of possible inefficiencies under different support schemes

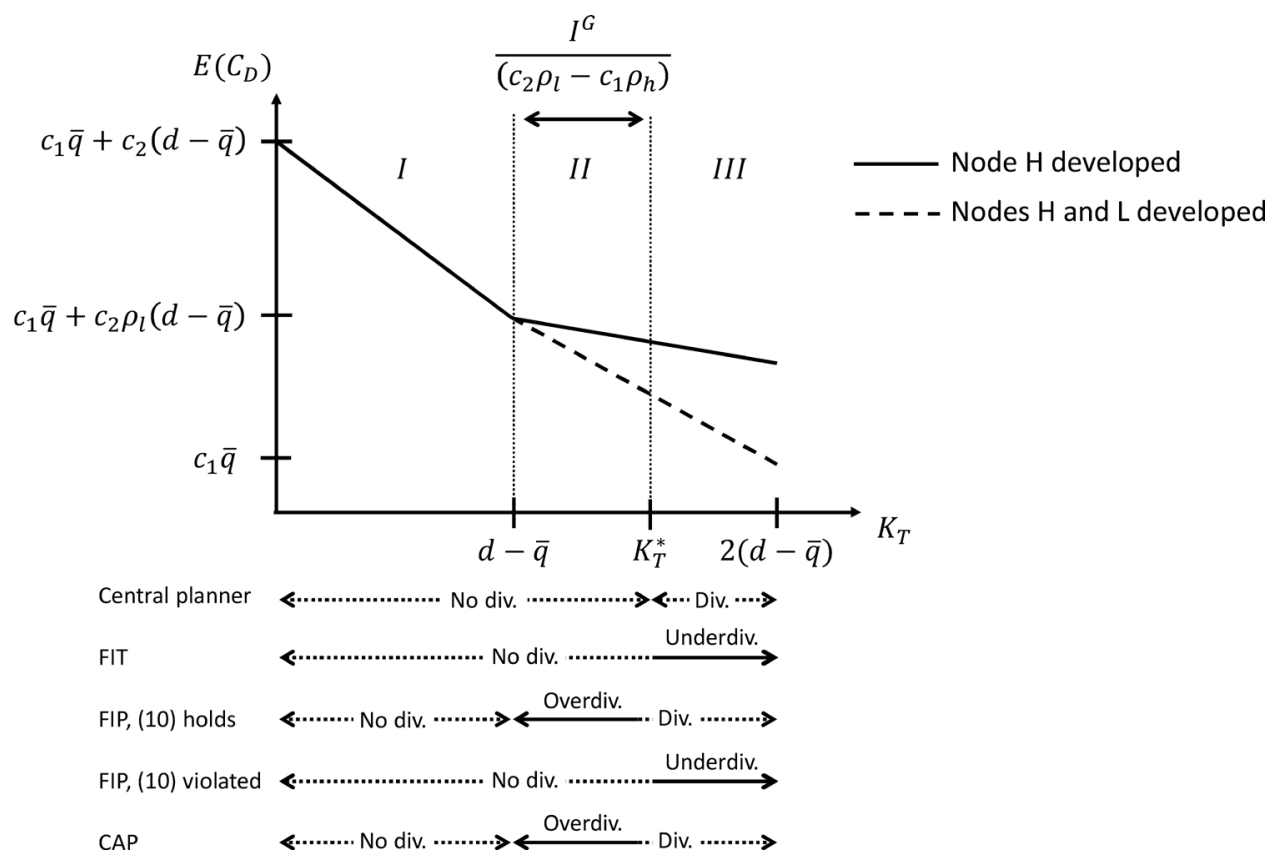

is analogous to Figure 3 and shows expected dispatch costs as a function of the capacity target for renewable electricity generation $K_{T}$. Additionally, Figure 4 shows the model results and the resulting inefficiencies in an unbundled system with reactive grid investment compared to the central planner solution. $K_{T}^{*}$ indicates the capacity target above which the central planner develops the low wind location $L$.

Figure 4 shows that for low renewable targets $K_{T} \leq(d-\bar{q})$ all support mechanisms lead to the efficient system configuration with only node $H$ developed, which corresponds to area $I$. For moderate renewable targets $(d-\bar{q})<K_{T} \leq K_{T}^{*}$ in area $I I$, only the feed-in tariff system guarantees the optimal solution, while capacity payments lead to overdiversification and the feed-in premium system leads to overdiversification if condition (10) holds. For high renewable targets $K_{T}>K_{T}^{*}$ in area III on the other hand, only capacity payments guarantee the efficient system configuration, while the feed-in tariff system leads to underdiversification and the feed-in premium system leads to underdiversification if condition (10) is violated.

The resulting inefficiencies can be further analyzed by comparing total system costs of the central planner solution to a system with under- or overdiversified wind locations. The corresponding welfare effects are described by Equations (14a) and (14b):

$$
\begin{aligned}
& \Delta W^{\text {overdiv. }}=I^{G}-\left(c_{2} \rho_{l}-c_{1} \rho_{h}\right)\left(K_{T}-(d-\bar{q})\right)\left(\text { for }(d-\bar{q})<K_{T} \leq K_{T}^{*}\right) \\
& \Delta W^{\text {underdiv. }}=\left(c_{2} \rho_{l}-c_{1} \rho_{h}\right)\left(K_{T}-(d-\bar{q})\right)-I^{G} \quad\left(\text { for } K_{T}>K_{T}^{*}\right)
\end{aligned}
$$

Equation (14a) expresses the welfare loss due to overdiversification of wind locations. It can be seen that the welfare loss is decreasing in $K_{T}$ and increasing in $\bar{q}$. The slope of both effects is higher if the conventional merit order is steep and the quality difference between the wind locations is small. Additionally it can be seen that the welfare loss due to overdiversification is limited to $I^{G}$. Equation (14b) expresses the corresponding welfare loss due to underdiversification of wind loca- 
tions, which is increasing in $K_{T}$ and decreasing in $\bar{q}$. Equivalently, these effects are more pronounced with a steep merit order and a small difference between expected wind generation at the two locations. The possible welfare loss due to underdiversification is theoretically unbounded.

In practice, climate policy measures typically include explicit renewable targets as well as reductions of emission intensive, for example coal-fired, base-load capacity. ${ }^{22}$ Hence, the model parameters $K_{T}$ and $\bar{q}$ are typically directly influenced by policy makers. As a result, the following policy implications can be derived based on the discussed welfare effects and the results in Figure 4.

First, the choice of the support scheme is uncritical for low renewable targets as all assessed policies yield the efficient solution with only the best wind location developed. Second, overdiversification of locations should be of concern for moderate renewable targets. Consequently a feed-in tariff system may be the best solution. Alternatively the TSO can act proactively, for example by assigning a limited number of good wind locations and commit to not connecting additional sites. Third, market based mechanisms are important for high renewable targets as the value of diversification of wind locations increases. Consequently, capacity subsidies should be implemented. Alternatively a feed-in premium system can be optimal if condition (10) is violated. This is however difficult for policy makers to assess in practice as the development of crucial parameters such as marginal conventional generation costs or wind power investment costs is subject to major uncertainty. If high renewable targets are implemented with a feed-in tariff system or a feed-in premium system and condition (10) holds, the TSO can only prevent inefficiencies by building transmission lines in advance of generation investment and limiting transmission capacity optimally in order to enforce diversification of wind locations. This is probably difficult to realize in practice as substantial planning efforts are required. Fourth, politically induced reductions of base load capacity decrease the profitability of developing both wind locations as more peak load generation can be displaced by wind power generation from the better wind location. As a result, potential welfare losses due to underdiversification of locations can be dampened. Welfare losses caused by overdiversification on the other hand are increased by reductions in base load capacity. ${ }^{23}$

The discussed policy implications are derived under the assumption of no endogenous changes in conventional power generation capacities. This assumption is uncritical in the short to medium term because wind power investment has significantly lower lead times compared to conventional power plant investments. In the long term however, the addition of intermittent wind power capacities is likely to induce changes in the structure of the conventional power plant fleet, which in turn influences market based investment into wind power. An analysis of these feedback effects is out of the scope of the paper. An extension of the presented model with endogenous investments into conventional power generation is an interesting direction for future research.

\subsection{Numerical analysis}

Based on the analysis in the previous section it can be stated that the two main components that determine the level of inefficiency described by Equations (14a) and (14b) are the grid investment costs $I^{G}$ and the benefit of diversification $\left(c_{2} \rho_{l}-c_{1} \rho_{h}\right)\left(K_{T}-(d-\bar{q})\right)$. Both components

22. Examples for policy measures that directly influence base load capacity are emission standards, which have been introduced for example in the United States, the European Union, China or India. Additionally, several countries have directly influenced base load generation capacity by shutting down coal-fired generation or putting restrictions on investments into new power generation, see International Energy Agency (2016). A specific policy that combines the introduction of a feed-in tariff scheme with shut-downs of coal fired power plants is discussed in Stokes (2013) for the case of Ontario, Canada.

23. Note that regardless of the subsidy mechanism, the expected costs of conventional generation increase due to politically enforced reductions in base load generation capacity. 
can be substantial in practice. An analysis of about 250 transmission projects in Europe in Agency for the Cooperation of Energy Regulators (2015) reports for example median total investment costs of roughly 1 million EUR per kilometer for 2 circuit overhead transmission lines at 380-400 kV voltage. Consequently, overdiversification of wind locations can yield substantial inefficiencies if too many remote wind sites than necessary are developed. For underground cables the equivalent investment costs are almost 6 million EUR per kilometer. In countries where underground cables are increasingly discussed because of public opposition against overhead lines the issue of overdiversification can be therefore even more pressing. A detailed assessment of the benefit of diversification of wind locations in real world power systems requires detailed statistical analysis and modeling and is therefore out of the scope of this paper. However, a simple estimation based on fuel prices and full load hours of wind power plants in Germany suggests that the potential benefits can be substantial. Methodology and results of the analysis are described in this section.

The marginal generation costs of conventional power plants $c_{1}$ and $c_{2}$ are assumed to be $30 \mathrm{EUR} / \mathrm{MWh}$ and $60 \mathrm{EUR} / \mathrm{MWh}$ which corresponds roughly to the marginal costs of a coal-fired power plant and an open cycle gas turbine in Europe. The probabilities for wind power production are determined based on full load hours of modern wind power plants in northern and southern Germany. 2600 full load hours for northern Germany as node $H$ and 2100 full load hours for southern Germany as node $L$ are assumed. The values of and in Equations (14a) and (14b) are the probabilities that only one of the two locations produces electricity while the other does not. Consequently, additional assumptions on the correlation of wind power generation at the two locations have to be made. In the model, the correlation is determined by, which is the probability that both locations produce at the same time. In the numerical example an additional state with probability and no wind power production is introduced in order to better reflect real world wind power production.

The relevant probabilities are determined based on a simple logic: When assuming the maximum negative correlation based on the real world full load hours there are 2600 hours of wind production only at node $H$ and 2100 hours of wind production only at node $L$ while the hours of parallel wind production at both nodes are 0 . With 8760 hour per year, the corresponding probabilities are, and . If the maximum positive correlation is assumed, there are 2100 hours of parallel production and 500 hours of production only at node $H$. The corresponding probabilities are , and . The probabilities between the two explained extreme cases are scaled linearly based on the ratio between full load hours at nodes $H$ and $L$. The benefit of diversification is then calculated based on Equations (14a) and (14b) with . The result can be interpreted as the yearly benefit of building one MW of wind power capacity at the low wind location $L$ instead of the high wind location $H$ for renewable targets. The results are depicted in Figure 5 as a function of the correlation coefficient between wind generation at nodes $H$ and $L$. The correlation coefficient is calculated with the corresponding values for, and .

Figure 5 shows that there is no benefit of diversifying wind locations for high correlations. The break even for diversification is at a correlation of 0.66 . For the extreme case of maximum negative correlation the benefit of diversification increases to almost 50000 EUR/MW per year. An analysis of real world correlation between wind power generation in the different federal states in Germany is conducted in Hagspiel (2018). The analysis shows that the real world correlation is in a range between 0.1 and 0.77 with a mean of 0.48 . The feasible range is indicated by the dashed lines in Figure 5. Additionally, the dotted line indicates the mean correlation. It can be seen that the potential yearly benefit of diversification is at roughly $10000 \mathrm{EUR} / \mathrm{MW}$ for the mean correlation and $30000 \mathrm{EUR} / \mathrm{MW}$ for the minimum correlation. The negative value for the maximum correlation 
Figure 5: Yearly benefit of diversification in the numerical example

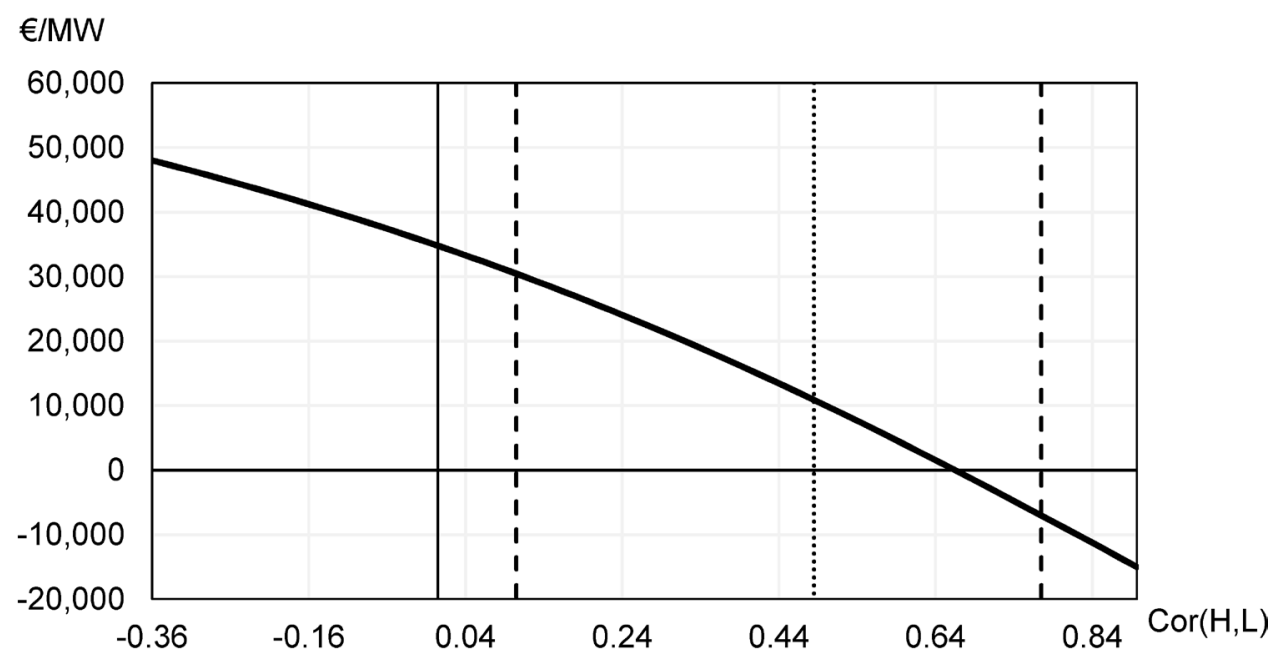

shows that diversification is not necessarily beneficial but depends on the specific wind conditions at the given locations.

The numerical analysis shows, that there can be substantial benefits of diversification in real world power systems. However, the presented example can only give a first indication. A detailed analysis for real world power systems with different supply curves of conventional generation and different wind conditions is a promising direction for future research.

\section{MODEL EXTENSIONS}

After the basic results and implications of the model have been discussed, this section introduces extensions that give additional insights on the coordination problem between subsidized renewable energy investments and grid investments in unbundled electricity systems.

\subsection{Asymmetric grid investment costs}

Throughout Section 2 symmetric investment costs for grid investments are assumed, which means that investments costs for transmission lines to nodes $H$ and node $L$ are equal. In reality, the required costs to integrate different wind location into the electricity system can vary substantially based on factors such as the distance to load centers or effects on bottlenecks within the system. Introducing asymmetric investment costs for grid extensions does not change the dispatch problem nor the investment problem of wind power producers. However, the first-best benchmark solution of the central planner and the transmission investment problem are different. The main difference to the solutions presented in Section 2 is that connecting only node $L$ is not dominated by connecting only node $H .^{24}$

As a result, additional inefficiencies can occur when the transmission line to the high wind location $H$ is more costly than the transmission line to the low wind location $L$. In this case it is pref-

24. Note that a setting with two nodes where demand is located at one node and wind power investment is possible at both nodes can be modeled by setting grid investment costs for the connection to node $H$ or node $L$ to zero. The two node setting is therefore a special case of the three node model with asymmetric grid investment costs. 
erable to connect only node $L$ if the higher expected wind output at node $H$ does not justify the additional grid investment costs. If wind power investors move first they will however prefer the better wind location $H$ and therefore force the transmission operator to build the more costly transmission line. Analogous to Section 2 a perfectly regulated and perfectly informed transmission operator can implement the first best solution by anticipating investment decisions of wind power producers and building the optimal network configuration proactively. The mathematical formulation of the central planner problem with asymmetric grind investment costs is provided in Appendix A.2.1.

The case of asymmetric grid investment costs has practical relevance because in existing electricity systems there are typically suitable areas for wind power production close to demand centers or existing grid infrastructure which can be integrated at comparably low costs. The areas with the best wind properties on the other hand are often remote and are thus costly to connect to the existing infrastructure. Lamy et al. (2016) show for example that developing the best wind locations in the United States could be inefficient if transmission extensions are included in the assessment. Similarly, Wu et al. (2014) argue that the renewable support mechanism in China incentivized large wind power investments in central China, where the best wind locations are located. However, these areas are far away from the coastal industrial demand centers and therefore costly to connect to the existing grid infrastructure. As a result up to a third of the installed wind power capacity in China is idle and lacks proper grid connection. Against the backdrop of these practical examples the present theoretical analysis underlines the importance of a well designed regulatory system that coordinates private wind power investment and grid extensions.

\subsection{Imperfect regulation}

The results in Section 2 are based on the assumption of benevolent behavior of the transmission operator as a result of perfect regulation. In reality transmission companies are not perfectly regulated and follow their own agenda inside the regulatory constraints. Depending on the regulatory system incentives to overinvest or underinvest compared to the socially optimal network configuration can emerge. Regulatory systems that incentivize overinvestment according to standard economic theory are cost-plus and rate-of-return regulation. ${ }^{25}$ Under rate-of-return regulation the transmission operator is allowed to recover investment costs and to earn an additional rate of return which is set by the regulator. In the analyzed model a revenue maximizing transmission operator under rate of return regulation profits from building transmission lines to both wind locations. Hence, given the decision variables from Section 2.4, the transmission operator can limit the transfer capacity to node $H$ to a value below the renewable target in order to force wind power investors to develop both locations in all considered subsidy systems. ${ }^{26}$ Proactive behavior therefore enables the transmission operator to always build both transmission lines and earn the guaranteed revenue.

An example for a regulatory system that incentivizes underinvestment is price-cap regulation with no adjustments of the cap based on the investment activity of the transmission operator. ${ }^{27}$ In such a regulatory system the transmission operator would try to build as little transmission capacities as possible. Assuming that the transmission operator acts proactively and is obliged to enable

25. See for example Averch and Johnson (1962).

26. It is assumed that the transmission operator is not able to connect a location where no wind power capacity will be built in the second stage. Therefore he has to limit transfer capacity in order to steer investments.

27. For a detailed discussion of the effects of price-cap regulation on investment behavior see for example Laffont and Tirole (1993). Modern regulatory systems based on incentive and yardstick regulation can also be seen as a type of price-cap regulation where the price-cap is revised regularly based on industry benchmarks, see Joskow (2014). A comparison of rateof-return and price-cap regulation can be found in Liston (1993). 
the realization of the renewable target, it would be optimal to connect only one wind location. With symmetric grid investment costs, the transmission operator is indifferent between the locations. With asymmetric investment costs he connects only the location with lower grid investment costs.

The two examples show that imperfect regulation can lead to substantial inefficiencies in grid investment when the transmission operator invests proactively in an unbundled electricity system. A more detailed analysis of the impact of different regulatory regimes on the coordination problem between renewable energy investment and grid investment is left for further research.

\subsection{G-component}

One of the main results of Section 2 is that wind power investors do not necessarily choose system optimal locations for their investments. Additionally it has been shown that proactive behavior of a benevolent transmission operator leads to the optimal system configuration, which is however only applicable under perfect regulation. An alternative approach to directly influence the investment behavior of wind power investors is a location dependent g-component. A g-component is a network charge which is set by the regulator and paid by power generators for the electrical energy they feed into the grid. This section analyzes if such a charge can be set to a level that reflects the impact of investments into new generation capacity on overall system costs, leading to an internalization of the external effects of private investments.

A g-component is not applicable in a feed-in-tariff system because the lack of market signals for investors does not incentivize diversification of locations. Therefore a g-component could only shift investments entirely from the high wind location to the low wind location. In feed-in premium systems however, a g-component can alter the relationship between the revenue generated from spot market sales and fixed premium payments which determines the profitability of diversification for investors. Consequently, a g-component can adjust the investment problem of private investors, formulated in Equation (9) in order to harmonize it with Proposition 1.

Assuming that developing the low wind location is socially inefficient, the regulator can choose to charge a g-component at location $L$ in order to deincentivize private investments. By introducing the g-component $G_{L}$ into Equation (9) and combining it with Proposition 1, the following lower bound for $G_{L}$ can be derived:

$$
G_{L} \geq \frac{I^{G}}{\left(K_{T}-(d-\bar{q})\right)\left(\rho_{l}+\rho_{l h}\right)}-\frac{\left(\rho_{h}-\rho_{l}\right) * F I P}{\left(\rho_{l}+\rho_{l h}\right)}
$$

The first term in Equation (15) shows that the g-component introduces the grid investment costs as well as the renewable target $K_{T}$ into the maximization problem of wind power investors. The minimum value of $G_{L}$ increases with $I^{G}$ and decreases with $K_{T}$ because the social costs of developing the low wind location $L$ are high if the connection is costly and if only small amounts of wind power capacity are built at node $L$, which still require the full lumpy grid investment. The second term in Equation (15) results from the higher fixed premium payments at node $H$ and reduces the lower bound for $G_{L}$.

A lower bound for $G_{H}$ in order to incentivize investments at node $L$ can be derived analogously, the results are provided in Appendix A.2.2. Similarly to the feed-in premium case, a g-component can be used to steer locational choices of private investors in a subsidy system with direct capacity payments. The resulting lower bound for $G_{L}$ to prevent potential overdiversification can be obtained by setting FIP to zero in the solution of the feed-in premium case. Underdiversification of wind locations is not possible in a system with direct capacity payments as shown in Section 2.3.3. 


\section{CONCLUSION}

This article analyzes interactions between the locational choice of private wind power investors in unbundled electricity systems under different subsidy schemes and the required grid investments to integrate the wind power capacity into the system. I find that private investors do not choose system optimal wind locations in feed-in tariff schemes, feed-in premium schemes and subsidy systems with direct capacity payments. In feed-in tariff schemes inefficiencies result from the lack of internalization of the market value of the produced electricity into investment decisions. Under feed-in premium schemes and capacity subsidies the market value is internalized, but the system integration costs are not. Consequently, all three subsidy systems can result in inefficient system configurations if the transmission operator follows wind power investments.

The described inefficiencies can be prevented if a benevolent transmission operator anticipates investment decisions of private investors and steers investment in a system optimal way. Consequently, anticipative transmission investment can help to efficiently integrate generation capacities based on renewable energy sources into electricity systems. However, benevolent behavior is only applicable under perfect regulation. In absence of perfect regulation, incentives to implement the system configuration that maximizes the profit of the transmission operator inside the regulatory constraints arise. A possibility to directly influence investment decisions of private investors by internalizing the system integration costs are location dependent grid charges for power producers.

The results of the analysis show that support schemes for renewable electricity generation should be designed with awareness for the consequences on the locational choice of investors. In addition, policy makers should assign a more active role to transmission operators, which acknowledges the importance of anticipative investment behavior. However, inefficient steering of renewable investments by transmission companies as a result of imperfect regulation should be of concern. Finally it is shown that power systems which internalize not only the market value of electricity but also the location dependent integration costs for generation capacities into private investment decisions should be designed.

In future work, the model can be extended with more complex representations of stochastic wind generation. Another possibility for further research is an application of the model with real world power systems in order to quantify the inefficiencies of uncoordinated renewable energy and grid investments. Also an extension with endogenous investment into conventional generation, multiple renewable technologies or the introduction of incomplete information of the transmission operator regarding the quality of wind locations are promising additions.

\section{APPENDIX}

\section{A.1 Proofs}

\section{Proof of Proposition 1.}

The problem can be solved by comparing the different network configurations. $L_{L}=0$ enforces $L_{H}=1$ and $\operatorname{Cap}_{H}=K_{T} . L_{H}=0$ enforces $L_{L}=1$ and $\operatorname{Cap}_{L}=K_{T}$. If $L_{L}=1$ and $L_{H}=1$, $\operatorname{Cap}_{H}+\operatorname{Cap}_{L}=K_{T}$ follows. $L_{H}=0$ and $L_{L}=0$ can be immediately ruled out because of $K_{T}>0$.

For $K_{T} \leq(d-\bar{q}), \frac{\partial \mathbf{E}\left(C_{D}\right)}{\partial \operatorname{Cap}_{H}}<\frac{\partial \mathbf{E}\left(C_{D}\right)}{\partial \operatorname{Cap}_{L}}$ holds because of $\rho_{h}>\rho_{l}$. It follows that $L_{L}=1$ and $\mathrm{Cap}_{L}>0$ is never optimal, which is equivalent to the first part of Proposition 1. 
For $K_{T}>(d-\bar{q})$ several cases have to be compared. Because $\mathbf{E}\left(C_{D}\right)$ is piecewise linear and strictly decreasing in $K_{H}$ and $K_{L}$ the optimal solution must be either $\operatorname{Cap}_{H}=K_{T}$ and $\operatorname{Cap}_{L}=0$, $\operatorname{Cap}_{H}=0$ and $\operatorname{Cap}_{L}=K_{T}, \operatorname{Cap}_{H}=d-\bar{q}$ and $\operatorname{Cap}_{L}=K_{T}-(d-\bar{q})$ or $\operatorname{Cap}_{H}=K_{T}-(d-\bar{q})$ and $\operatorname{Cap}_{L}=(d-\bar{q})$. Because of $\rho_{h}>\rho_{l}$ the solution $\operatorname{Cap}_{H}=K_{T}$ and $\operatorname{Cap}_{L}=0$ dominates $\operatorname{Cap}_{H}=0$ and $\operatorname{Cap}_{L}=K_{T}$ and $\operatorname{Cap}_{H}=d-\bar{q}$ and $\operatorname{Cap}_{L}=K_{T}-(d-\bar{q})$ dominates $\operatorname{Cap}_{H}=K_{T}-(d-\bar{q})$ and $\operatorname{Cap}_{L}=(d-\bar{q})$ for $K_{T} \leq 2(d-\bar{q})$. Plugging the remaining candidates for the cost minimum into Equations (4) and (6a) and comparing the results yields the second part of Proposition 1 after some reformulation.

\section{Proof of Proposition $2 a$.}

Plugging Equations (3a), (3b) and (3c) into Equation (7a) and taking the first derivative with respect to $K_{H}$ and $K_{L}$ yields $\frac{\partial \mathbf{E}\left(\pi_{i}\right)}{\partial K_{H}}>\frac{\partial \mathbf{E}\left(\pi_{i}\right)}{\partial K_{L}}$ because of $\rho_{h}>\rho_{l} . L_{H}=1$ and $L_{L}=1$ can be assumed for reactive behavior of the transmission operator as transmission lines are built according to wind power investment.

\section{Proof of Proposition $2 b$.}

Equation (8a) can be reformulated as follows with $K_{A, i}=K_{H, i}+K_{L, i}$ :

$$
\mathbf{E}\left(\pi_{i}\right)=\left\{\begin{array}{r}
\left(F I P+c_{1}\right)\left(\rho_{h} K_{H, i}+\rho_{l} K_{L, i}+\rho_{h l} K_{A, i}\right)-I^{W} K_{A, i} \\
\quad \text { if } \sum_{i} K_{H, i}>d-\bar{q}, \sum_{i} K_{L, i}>d-\bar{q} \\
\left(F I P+c_{2}\right) \rho_{l} K_{L, i}+\left(F I P+c_{1}\right)\left(\rho_{h} K_{H, i}+\rho_{h l} K_{A, i}\right)-I^{W} K_{A, i} \\
\text { if } \sum_{i} K_{H, i}>d-\bar{q}, \sum_{i} K_{L, i} \leq d-\bar{q} \\
\left(F I P+c_{2}\right) \rho_{h} K_{H, i}+\left(F I P+c_{1}\right)\left(\rho_{l} K_{L, i}+\rho_{h l} K_{A, i}\right)-I^{W} K_{A, i} \\
\text { if } \sum_{i} K_{H, i} \leq d-\bar{q}, \sum_{i} K_{L, i}>d-\bar{q} \\
\left(F I P+c_{2}\right)\left(\rho_{h} K_{H, i}+\rho_{l} K_{L, i}\right)+\left(F I P+c_{1}\right) \rho_{h l} K_{A, i}-I^{W} K_{A, i} \\
\text { if } \sum_{i} K_{H, i} \leq d-\bar{q}, \sum_{i} K_{L, i} \leq d-\bar{q}, \sum_{i} K_{A, i}>d-\bar{q} \\
\left(F I P+c_{2}\right)\left(\rho_{h} K_{H, i}+\rho_{l} K_{L, i}+\rho_{h l} K_{A, i}\right)-I^{W} K_{A, i} \\
\text { if } \sum_{i} K_{H, i} \leq d-\bar{q}, \sum_{i} K_{L, i} \leq d-\bar{q}, \sum_{i} K_{A, i} \leq d-\bar{q}
\end{array}\right.
$$

The partial derivatives with respect to $K_{H, i}$ and $K_{L, i}$ are:

$$
\begin{aligned}
& \frac{\partial \mathbf{E}\left(\pi_{i}\right)}{\partial K_{H, i}}= \begin{cases}\left(F I P+c_{1}\right)\left(\rho_{h}+\rho_{h l}\right)-I^{W} & \text { if } \sum_{i} K_{H, i}>d-\bar{q} \\
\left(F I P+c_{2}\right) \rho_{h}+\left(F I P+c_{1}\right) \rho_{h l}-I^{W} & \text { if } \sum_{i} K_{H, i} \leq d-\bar{q}, \sum_{i} K_{A, i}>d-\bar{q} \\
\left(F I P+c_{2}\right)\left(\rho_{h}+\rho_{h l}\right)-I^{W} & \text { if } \sum_{i} K_{H, i} \leq d-\bar{q}, \sum_{i} K_{A, i} \leq d-\bar{q}\end{cases} \\
& \frac{\partial \mathbf{E}\left(\pi_{i}\right)}{\partial K_{L, i}}= \begin{cases}\left(F I P+c_{1}\right)\left(\rho_{l}+\rho_{h l}\right)-I^{W} & \text { if } \sum_{i} K_{L, i}>d-\bar{q} \\
\left(F I P+c_{2}\right) \rho_{l}+\left(F I P+c_{1}\right) \rho_{h l}-I^{W} & \text { if } \sum_{i} K_{L, i} \leq d-\bar{q}, \sum_{i} K_{A, i}>d-\bar{q} \\
\left(F I P+c_{2}\right)\left(\rho_{l}+\rho_{h l}\right)-I^{W} & \text { if } \sum_{i} K_{L, i} \leq d-\bar{q}, \sum_{i} K_{A, i} \leq d-\bar{q}\end{cases}
\end{aligned}
$$


Because of the assumption of free market entry, investors develop the locations in descending order of marginal revenue. For $K_{T} \leq(d-\bar{q}), \frac{\partial \mathbf{E}\left(\pi_{i}\right)}{\partial K_{H, i}}>\frac{\partial \mathbf{E}\left(\pi_{i}\right)}{\partial K_{L, i}}$ holds and $\operatorname{Cap}_{L}>0$ is never optimal. For $K_{T}>(d-\bar{q})$, comparing (17) and (18) yields Equation (9).

\section{Proof of Proposition 2c.}

The capacity subsidy is equivalent to a reduction of the investment costs for wind power $I^{W}$. Consequently, the optimal solution can be derived analogously to Proposition $2 \mathrm{~b}$ with $F I P=0$.

Proof of Proposition 3.

$L_{H}=1$ and $L_{L}=0$ implements $\operatorname{Cap}_{H}=K_{T}$ and $\operatorname{Cap}_{L}=0$, the first part of Proposition 3 follows.

If the transmission operator decides to limit transfer capacity $\overline{L_{H}}$ two cases can be distinguished. If $\mathrm{Cap}_{H} \leq \overline{L_{H}}$ the decision problem for renewable investors is unchanged compared to Propositions 2a, 2b and 2c. For $\operatorname{Cap}_{H}>\overline{L_{H}}$, the marginal revenue $\frac{\partial \mathbf{E}\left(\pi_{i}\right)}{\partial \operatorname{Cap}_{H, i}}$ equals $-I^{W}$, so $\operatorname{Cap}_{H} \leq \overline{L_{H}}$ in the competitive case. In the monopolistic case, $\operatorname{Cap}_{H, i}$ can be substituted by $\overline{L_{H}}$ in the definition of the five cases in Equation (16). Comparing this adjusted Equation (16) with $\operatorname{Cap}_{H}=\overline{L_{H}}$ to $\operatorname{Cap}_{H}>\overline{L_{H}}$ shows that $\mathbf{E}\left(\pi_{i}\left(\operatorname{Cap}_{\underline{H}}=\overline{L_{H}}\right)\right)>\mathbf{E}\left(\pi_{i}\left(\operatorname{Cap}_{H}>\overline{L_{H}}\right)\right)$. Consequently the transmission operator chooses $L_{H}=1, L_{L}=1$ and $\overline{L_{H}}=(d-\bar{q})$ if it is optimal according to Proposition 1.

\section{A.2 Extensions}

\section{A.2.1 Asymmetric grid investment costs}

Introducing asymmetric investment costs leads to the following expression for total system costs:

$$
C_{\text {Total }}=\mathbf{E}\left(C_{D}\right)+I^{W}\left(\operatorname{Cap}_{H}+\operatorname{Cap}_{L}\right)+I_{H}^{G} * L_{H}+I_{L}^{G} * L_{L}
$$

For $K_{T} \leq d-\bar{q}$ connecting both nodes $H$ and $L$ is dominated by connecting only node $H$ because it is always preferable to build all wind power capacity at the better wind location $H$ when both nodes are connected. Comparing the two possible outcomes for connecting one wind location leads to the condition in Equation (20) for developing the low wind location.

$$
c_{2}\left(\rho_{h}-\rho_{l}\right) K_{T}>I_{H}^{G}-I_{L}^{G}
$$

For renewable targets $K_{T}>d-\bar{q}$ all three possible network configurations have to be considered. Comparing the outcomes for the configurations with only one of the wind locations connected to the demand node $D$ leads to Equation (21a). Equation (21b) gives the condition for lower system costs when both wind nodes are connected compared to only node $H$ connected, Equation $(21 \mathrm{c})$ gives the condition for lower system costs when both wind nodes are connected compared to only node $L$ connected.

$$
\begin{aligned}
& \left(\rho_{h}-\rho_{l}\right)\left(c_{1}\left(K_{T}-(d-\bar{q})\right)+c_{2}(d-\bar{q})\right)>I_{H}^{G}-I_{L}^{G} \\
& \left(c_{2} \rho_{l}-c_{1} \rho_{h}\right)\left(K_{T}-(d-\bar{q})\right)>I_{L}^{G}
\end{aligned}
$$




$$
\left(c_{2}-c_{1}\right) \rho_{l}\left(K_{T}-(d-\bar{q})\right)+c_{2}\left(\rho_{h}-\rho_{l}\right)(d-\bar{q})>I_{H}^{G}
$$

\section{A.2.2 Additional expressions for g-component}

Introducing $G_{H}$ into Equation (9) and combining it with Proposition 1 yields:

$$
G_{H} \geq \frac{\left(\rho_{h}-\rho_{l}\right) * F I P}{\left(\rho_{h}+\rho_{l h}\right)}-\frac{I^{G}}{\left(K_{T}-(d-\bar{q})\right)\left(\rho_{h}+\rho_{l h}\right)}
$$

\section{ACKNOWLEDGMENTS}

I am grateful for helpful comments from Felix Höffler, Simon Paulus, Christian Tode, three anonymous referees and participants of the Research Colloquium in Energy Economics at the University of Cologne. Financial support by the German Research Foundation through grant HO 5108/2-1 is gratefully acknowledged. The responsibility for the content of this publication lies solely with the author.

\section{REFERENCES}

Agency for the Cooperation of Energy Regulators (2015). "Report on Unit Investment Cost Indicators and Corresponding Reference Values for Electricity and Gas Infrastructure".

Ambec, S. and C. Crampes (2012). "Electricity provision with intermittent sources of energy" Resource and Energy Economics 34(3): 319-336. https://doi.org/10.1016/j.reseneeco.2012.01.001.

Averch, H. and L. L. Johnson (1962). "Behavior of the Firm Under Regulatory Constraint" The American Economic Review 52(5): 1052-1069.

Bjørnebye, H., C. Hagem, and A. Lind (2018). “Optimal location of renewable power” Energy 147: 1203-1215. https://doi. org/10.1016/j.energy.2018.01.058.

Fischer, C. (2010). "Combining Policies for Renewable Energy: Is the Whole Less Than the Sum of Its Parts?” International Review of Environmental and Resource Economics 4(1): 51-92. https://doi.org/10.1561/101.00000030.

Fischer, C. and R. G. Newell (2008). "Environmental and technology policies for climate mitigation" Journal of Environmental Economics and Management 55(2): 142-162. https://doi.org/10.1016/j.jeem.2007.11.001.

Fürsch, M., S. Hagspiel, C. Jägemann, S. Nagl, D. Lindenberger, and E. Tröster (2013). "The role of grid extensions in a cost-efficient transformation of the European electricity system until 2050" Applied Energy 104: 642-652. https://doi. org/10.1016/j.apenergy.2012.11.050.

Gerlagh, R., S. Kverndokk, and K. E. Rosendahl (2009). “Optimal Timing of Climate Change Policy: Interaction Between Carbon Taxes and Innovation Externalities" Environmental and Resource Economics 43(3): 369-390. https://doi. org/10.1007/s10640-009-9271-y.

Hagspiel, S. (2018). "Reliability with interdependent suppliers" European Journal of Operational Research. https://doi. org/10.1016/j.ejor.2018.01.014.

Hiroux, C. and M. Saguan (2010). "Large-scale wind power in European electricity markets: Time for revisiting support schemes and market designs?” Energy Policy 38(7): 3135-3145. https://doi.org/10.1016/j.enpol.2009.07.030.

Höffler, F. and A. Wambach (2013). "Investment coordination in network industries: the case of electricity grid and electricity generation” Journal of Regulatory Economics 44(3): 287-307. https://doi.org/10.1007/s11149-013-9227-6.

International Energy Agency (2015). "Medium-Term Renewable Energy Market Report 2015”.

International Energy Agency (2016). "Energy and Air Pollution".

International Renewable Energy Agency (2015). "Renewable Energy Target Setting" .

Joskow, P. L. (2014). "Incentive regulation in theory and practice: electricity distribution and transmission networks" in "Economic Regulation and Its Reform: What Have We Learned?" , University of Chicago Press 291-344. https://doi. org/10.1111/j.0022-1821.2005.00253.x.

Joskow, P. L. and J. Tirole (2005). “Merchant Transmission Investment” Journal of Industrial Economics 53(2): $233-264$. 
Klessmann, C., C. Nabe, and K. Burges (2008). "Pros and cons of exposing renewables to electricity market risks-A comparison of the market integration approaches in Germany, Spain, and the UK" Energy Policy 36(10): 3646-3661. https:// doi.org/10.1016/j.enpol.2008.06.022.

Kunz, F. (2013). "Improving Congestion Management: How to Facilitate the Integration of Renewable Generation in Germany" The Energy Journal 34(4). https://doi.org/10.5547/01956574.34.4.4.

Laffont, J.-J. and J. Tirole (1993). A Theory of Incentives in Procurement and Regulation The MIT Press.

Lamy, J. V., P. Jaramillo, I. L. Azevedo, and R. Wiser (2016). "Should we build wind farms close to load or invest in transmission to access better wind resources in remote areas? A case study in the MISO region" Energy Policy 96: 341-350. https:// doi.org/10.1016/j.enpol.2016.06.011.

Liston, C. (1993). "Price-cap versus rate-of-return regulation" Journal of Regulatory Economics 5(1): 25-48. https://doi. org/10.1007/BF01066312.

Madrigal, M. and S. Stoft (2012). Transmission Expansion for Renewable Energy Scale-Up The World Bank.

Milstein, I. and A. Tishler (2015). "Can price volatility enhance market power? The case of renewable technologies in competitive electricity markets" Resource and Energy Economics 41: 70-90. https://doi.org/10.1016/j.reseneeco.2015.04.001.

Munoz, F. D., E. E. Sauma, and B. F. Hobbs (2013). “Approximations in power transmission planning: implications for the cost and performance of renewable portfolio standards" Journal of Regulatory Economics 43(3): 305-338. https://doi. org/10.1007/s11149-013-9209-8.

National Renewable Energy Laboratory (2012). "Renewable Electricity Futures Study" .

Obermüller, F. (2017). "Build wind capacities at windy locations? Assessment of system optimal wind locations" EWI Working Paper 17/09.

Pechan, A. (2017). "Where do all the windmills go? Influence of the institutional setting on the spatial distribution of renewable energy" Energy Economics 65: 75-86. https://doi.org/10.1016/j.eneco.2017.04.034.

Pozo, D., J. Contreras, and E. Sauma (2013). "If you build it, he will come: Anticipative power transmission planning" Energy Economics 36: 135-146. https://doi.org/10.1016/j.eneco.2012.12.007.

Sauma, E. E. and S. S. Oren (2006). "Proactive planning and valuation of transmission investments in restructured electricity markets" Journal of Regulatory Economics : 358-387. https://doi.org/10.1007/s11149-006-9012-x.

Schmidt, J., G. Lehecka, V. Gass, and E. Schmid (2013). "Where the wind blows: Assessing the effect of fixed and premium based feed-in tariffs on the spatial diversification of wind turbines" Energy Economics 40: 269-276. https://doi. org/10.1016/j.eneco.2013.07.004.

Stokes, L. C. (2013). "The politics of renewable energy policies: The case of feed-in tariffs in Ontario, Canada" Energy Policy 56: 490-500. https://doi.org/10.1016/j.enpol.2013.01.009.

Swider, D. J., L. Beurskens, S. Davidson, J. Twidell, J. Pyrko, W. Prüggler, H. Auer, K. Vertin, and R. Skema (2008). “Conditions and costs for renewables electricity grid connection: Examples in Europe" Renewable Energy 33(8): $1832-1842$. https://doi.org/10.1016/j.renene.2007.11.005.

Wu, Z., H. Sun, and Y. Du (2014). "A large amount of idle capacity under rapid expansion: Policy analysis on the dilemma of wind power utilization in China" Renewable and Sustainable Energy Reviews 32: 271-277. https://doi.org/10.1016/j. rser.2014.01.022.

Würzburg, K., X. Labandeira, and P. Linares (2013). "Renewable generation and electricity prices: Taking stock and new evidence for Germany and Austria" Energy Economics 40: 159-171. https://doi.org/10.1016/j.eneco.2013.09.011. 